\title{
Towards a specific modernity of architecture: the trade-off between text and context in defining a poetic approach of individual housing in Tunis
}

\author{
E. Bchir \\ Department of Architecture, \\ National School of Architecture and Urban Planning, Tunisia
}

\begin{abstract}
Our paper elaborates the idea of a specific modernity in architecture in the Tunisian context. We try to draft a process which extols modernity by reinterpreting local tradition with the aim of drawing a vision of dwelling poetics. To that end, a poetic phenomenological reading of the dwelling-building Heidegger's complex will be developed, by comparing narrated time and the constructed space relying on Paul Ricœur's hermeneutics. We compare architecture with narrative, a literary text with a spatial context and then we present our analytical model. We show how the three Aristotelian phases of mimetic invention are active and how they act as an intimate diachronic and synchronic trade-off between building and dwelling. The first phase examines $d$ welling under the phenomenological approach using Gaston Bachelard's topoanalysis that places poetic image at the heart of cultural reflection. The second phase presents the dialectic of $d$ welling and building focusing on building: space and time cross each other through construction and narration, and "spatiality of narration" tangles with the "temporality of the architectural act". We show how poetic reversals, intertextuality and intelligibility are relevant to architectural projects. The third phase highlights back $d$ welling and investigates the taste of the different protagonists involved in an architectural project.

The paper will examine the theoretical aspect and will equally focus on its applicability on a concrete case of individual housing in Tunis. The aim is to build up a view of an up-to-date architecture in harmony with its traditional local culture.

Keywords: architecture, modernity, tradition, Aristotelian poetics, narrative, building and dwelling, poetic image, individual housing.
\end{abstract}




\section{Introduction}

This research started from an observation of an international context increasingly intellectualizing architectural production, and a Tunisian context within globalization imports according to Habermas [1], the various "isms" of rationalism, socialism, capitalism, yet also brutalism, postmodernism, deconstructionism, etc. If, for the new demands of modern life, such as banking functions, airports, corporate headquarters or others, one could imagine an architecture independent from its local attributes, the same cannot be said for habitats which are mirrored by social and cultural structures embedded in a lifeworld. The question is then: what is the process by which the area of individual housing produces a specific modernity and an up-to date architecture in harmony with its local culture?

Paul Ricœur's parallel between architecture and narrative [2] is interesting, because it allows the application of the mechanisms of literary creation on architectural work through emplotment. Architecture would then be to space what the story is to time, a configuring act, made possible by the intersection of the narrative's spatiality with the architectural work's temporality. Points of interference between the two areas are fraught with subtlety: 1- constructed space as well as narrated time relate both to the Aristotelian mimetic invention, in the sense of a creative invention rooted in intertextuality and tradition. It would be dangerous to create the new without the old as a basis. Failure of the International Style in architecture has masterfully demonstrated it at its own expense. Similarly, configuration of space and time is expressed in entangling their dual properties: space is read as an abstraction expressing Cartesian coordinates of the geometric space where the points are all equivalent, at the same time, it is a living place for living bodies as described by Merleau-Ponty. Likewise, time presents itself in two ways, as cosmic time of clocks, and phenomenological time experiences. It is precisely in this entanglement of the two types of spaces, that the act of dwelling itself depends on the act of building. Dwelling and building are two sides of the same coin; no one can really determine which one precedes the other.

In this context, our paper aims at building up a poetic approach to architecture and establishing a process of creating a specific modernity, from four areas of reflection:

- Ricœur's hermeneutics based on Aristotelian poetics of emplotment [3];

- Heidegger's understanding of the dwelling-building complex, which links the spatial and temporal dimensions of architecture;

- Gaston Bachelard's topo-analysis [4], which questions the notion of dwelling through the phenomenology of the poetic image;

- Richness of meaning and the interference of various levels of perception and understanding as defined by Robert Venturi [5].

This parallel between constructed space and narrated time allowed us to reproduce the three stages of literary creation on architectural work, in order to define the three stages of spatiality. This will constitute the framework to study Heidegger's complex of the dwelling-building, where an intimate diachronic and 
synchronic overlap between building and dwelling emerges. Dwelling then takes over building at the stage of mimesis I or preconfiguration, while building takes over at the stage of mimesis II or configuration. Finally, dwelling again takes the center at the stage of mimesis III or refiguration. The developed three stages of the poetic structure will form the analytical frame of architectural space and are defined below.

\section{The poetic structure of an architectural work}

\subsection{Prefiguration: on dwelling}

The preconfiguration is the first stage in the architectural project before being drawn. Dwelling, put in the foreground, is apprehended through two viewpoints. The first is Bachelard's, which questions the poetic image of dwelling through imaginary. The second is Heidegger's, which manifests itself through the composition of these different images, called upon to concretize the relationship between building and $d$ welling in a real object. Dwelling therefore represents a staying with things. This conception has to do somewhere with memory, with being. And it is at the border of the lived space of the body itself and the geometric space that the act of $d$ welling will materialize in place, thanks to a building act.

\subsubsection{The house falls within Lebenswelt operations}

Lebesnwelt operations are those that result in an architecture considered part of the lifeworld. Analyzing these operations rests in analyzing how to:

- develop well-being places: it is about identifying these places;

- consider the boundary: it studies the relationship between the interior and the exterior as spatial areas unfolding from the street into the heart of the house;

- get shelter under a roof: how is the roof (flat, vaulted, etc.);

- move horizontally and vertically: it studies connection between spaces.

\subsubsection{The house is a body of images}

The house is both a vertical being and a concentrated being that establishes a dynamic dialectic between itself and the universe:

- as a vertical being: the house reflects a polarity differentiating itself vertically-wise. It will then examine the vertical stratification, which is the nature of spaces and the poles materializing verticality. We will pay particular attention to the connecting element between these different levels like stairs, ramps.

- as a concentrated being: the house raises the question of centrality. How can we reach the primitiveness of the hut? What are the well-being places that relate to the past and to dreamed-of situations: the dream palace and that of the hut.

- as a dialectic between the inside and the outside: what images are convened? What is the reversal capacity of the inside and the outside? 


\subsection{Configuration: to think building}

This stage is the backbone of the poetic analysis work. Studying the poetic structure of an architectural work through the relationship between building and $d w e l l i n g$, is to study its aesthetic, its distribution structures and the relationship between them, in a historical and a personal retrospection. In phenomenological terms, functional distribution levels represent traces and their quality will depend on functional complexity, while shapes represent masks, and the value of these will depend on social interaction with what the spatial object symbolizes. The poetic dimension is then represented by the relationship between the mask and the trace. The richer and more complex the relationship is, the greater it will be poetic. The act of building and dwelling overlap in a relationship in which past, present and future intertwine.

Thus, a systematic identification of architectonic elements is necessary. We have to identify the most complex elements of the functional point of view (traces) that can be read in terms of different formal scales (masks).

Three levels of reflection constitute configuration:

\subsubsection{Architectural praxis: the practical level}

The architectural act corresponds to emplotment in literature. Architectural configuration is to synthesize the different aspects of a building and to compose together living places, shapes and boundaries to achieve a given entity. This entity is expressed in its relationship between the whole and the parts. It is the same as an emplotment configurative act that puts together events and different points of view, as causes, motives and coincidences, producing concordance and discordance situations. Analyzing architectural configuration rests then on answering the following questions: How a structure that draws together the whole and the parts, is elaborated? How situations of concordance and discordance, characteristics of the Aristotelian plot, are achieving themselves through "poetic disasters", weaved in an architectural project?
Language (narrative)
(According to Aristotle)
Architecture (project)
The "peripeteia"
(According to Robert Venturi)
"Recognition"
"The double-functioning element"
"The phenomenon of Both-And"
"The tragic fall"
"The conventional element"

- Double form means the phenomenon of "both-and" in architecture. Because of a ranking of things at different levels of meaning, this phenomenon relates to the links between parts and the whole and is based on hierarchy.

- The double-functioning element denotes the movement and the idea of reversing the function. This is the trace: we have two functions, yet what is important is to see the connection between the two, not the fact that there are two functions.

- The conventional element denotes the use of an element in an unconventional manner, with the aim of creating surprise (e.g. postmodern architecture). 


\subsubsection{Intelligibility}

Intelligibility is the study of the coherence of the architectural project in an extended tradition understood in the sense of a lively transmission:

- What architectural composition is there?

- Is there a schema that uses notions like type, gender or other?

\subsubsection{Intertextuality}

Intertextuality in architecture evokes the idea of context, innovation and tradition. Analyzing intertextuality amounts to:

- studying buildings in their historical and social contexts, in their relation to others through the history of architecture;

- seeking for the relationship between innovation and tradition. What relationship is there to memory?

\subsection{Refiguration: re-reading dwelling through the World horizon of the user}

This third stage is about the re-evaluation of the build/dwell from a dwelling point of view. It examines the interaction of the world of the project designed by the architect with that of the user, in which the dwelling unfolds: how is the user living in the space, comparing to what was conceived in the project? Refiguration points then to a dialectic of space and time: the relationship with the other acting in space, and the relationship with oneself acting in time. This is the stage where the subject can be identified through the architectural object.

\subsubsection{Re-reading dwelling of the protagonists}

- Is there concordance with the imaginary that fueled the construction of the house with the lived space afterwards?

- What concordance with Lebenswelt operations is reflected in the project and what degree of adequacy with inhabiting the house?

\subsubsection{World horizon of the user and the architectural project}

The user lives in the building with its own abilities, in its own world horizon. It is not enough for the architect to think of a project, but it is necessary that his work meets the real needs of the inhabitant. This amounts to seeing the adequacy between what was thought by the architect with what is experienced by the inhabitant. This idea can be highlighted by the internal dynamics of the configuration of places within the architectural space, as suggested by the shaping of space designed by the architect and experienced by users.

\subsection{Conclusion: defining the elements of a specific poetics of modernity}

The study of narrative structures will allow us to draw out the transformation of the traditional poetics in order to provide research avenues for the development of a specific modern architecture. 
1) Prefiguration: The DWELL/Build Complex

The act of $d$ welling/building relates to:

* Lebenswelt spatiality, which is mostly corporal:

- Well-being places

- Consider the boundary...

- Get a shelter under a roof

- Move horizontally and vertically

* The house is a body of images:

- The house is a vertical being

- The house is a concentrated being

- The dialectic of the inside and the outside

2) CONFIGURATION: THINK BUILDING

The construction of a project in terms of a structure that brings together elements of the project and the ways of producing it.

* Architectural praxis: the spatial synthesis of the heterogeneous

- The relationship between the whole and the parts

- Poetic reversals

* Intelligibility: coherence of the architectural project

- Study of architectural composition and types

* Intertextuality

- The house in its historical and social contexts

- Tradition/innovation relationship

- Memory as traces of the possible

3) REFIGURATION: REREADING DWELLING IN THE USER'S WORLD HORIZON

* Re-reading the protagonist's $d$ welling

*Studying concordance between the user's world horizon and the architectural work

4) CONCLUSION: DEFINING ELEMENTS OF THE POETICS OF SPECIFIC MODERNITY

Figure 1: Analysis diagram of an architectural work.

\section{A poetic analysis}

In what follows, we present the results of a poetic analysis of a Tunisian contemporary house. We show how the architect has managed to transform traditional poetics by establishing an enriched relationship with the past, based on the diachronic and synchronic relationship between $d w e l l i n g$ and building.

The dialectic of the inside and the outside takes its meaning by designing at the same time the house project and the garden project, thus defining a multitude of well-being places, referring to past home and dreamed-of home. The spatial scenario is imagined, through an abstraction process, as differentiated extensions of full-light and shadowed interiors, separated by exterior green areas.

Ben Abdelkader's house is located in the city of Tunis. Set in a large family estate, the house is built on a ground floor and opens onto a beautiful view of the mountain Bou Kornine. It has no vis-à-vis. 


\subsection{Prefiguration}

\subsubsection{Lebenswelt spatiality}

3.1.1.1 Well-being places We can distinguish 3 places of well-being: the patio, the living-room, and the boudoir. Users like to sit in the patio in the shade of bougainvillea lived as a terrace swimming pool.

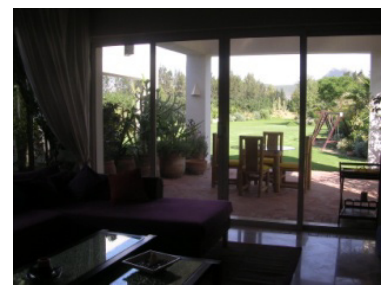

The patio from the living room.

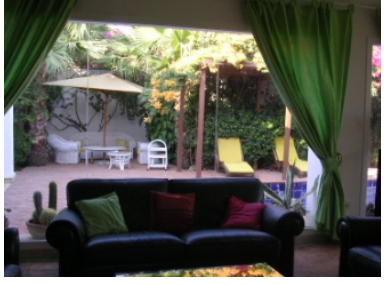

The garden from the living room.

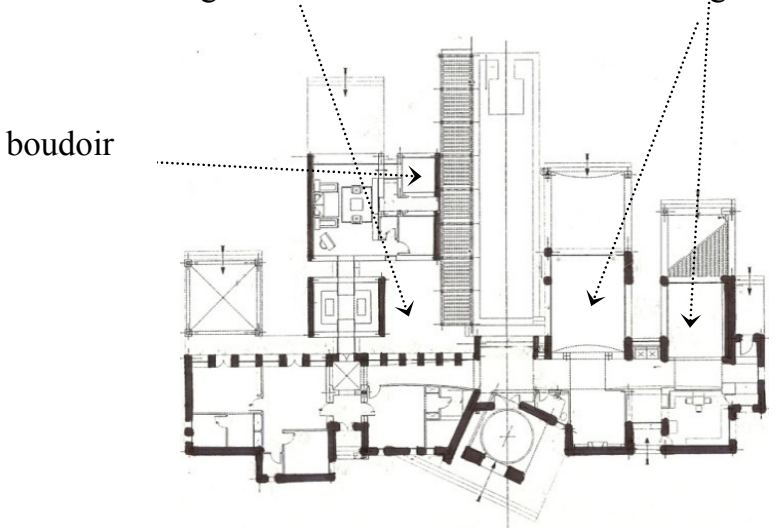

Figure 2: Contrast between the limits front/rear.

The boudoir (as indicated in figure 2) is the space of the well-being of the owner, in which he takes refuge. It stands as a cocoon wide open onto the garden, giving thus its subtlety to a modest space where an atmosphere of tranquility reigns. The living room offers a panoramic view on the garden and the mountain.

3.1.1.2 Consider the boundary Like the traditional house which differentiates the street facade from patio fronts, this house differentiates the front from the back. On arrival, the house presents itself as an almost blind facade, while at the back it opens totally onto the garden which constitutes then a re-interpretation of the traditional patio. A surprise effect is obtained. Moreover, construction materials have been used to delimit boundaries. The house is whitepainted coating, and visible red brick is just used on the entry front to frame the door, and on the right side as if it were to stop the deployment of the spaces. 
The garden terraces at the back are built of wood and border a transparent front, and the left side is completely blind, all painted in white. The four boundaries are adapted to their functions. A spatial synthesis of the heterogeneous is reached.

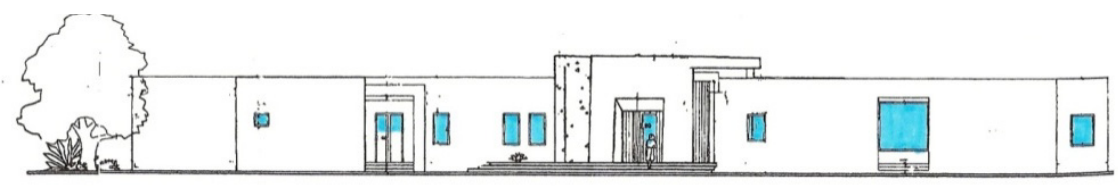

Figure 3: Entry front.

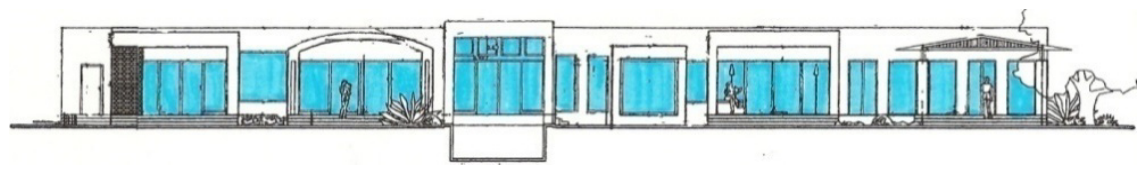

Figure 4: Garden front.

\subsubsection{The house is a body image}

3.1.2.1 About poetic image The house represents the past home and translates both the dream palace and the dream hut. The generosity of the distribution of space evokes the childhood's home of the owner with its multiple sqîfa (traditional space of the entry). It responds to the owner need for privacy translated by the architect into a logic that separates between private and collective spaces.

As a house of the past, Dar Ben Abdelkader is organized around a central void inspired by the patio theme, and the openness onto the mountain of Bou Kornine represents for the owner a homecoming to his childhood, where he spent his holidays. As a dream palace the house multiplies places and corners, extends distances and highlights thresholds. As a dream hut it displays its own simplicity.

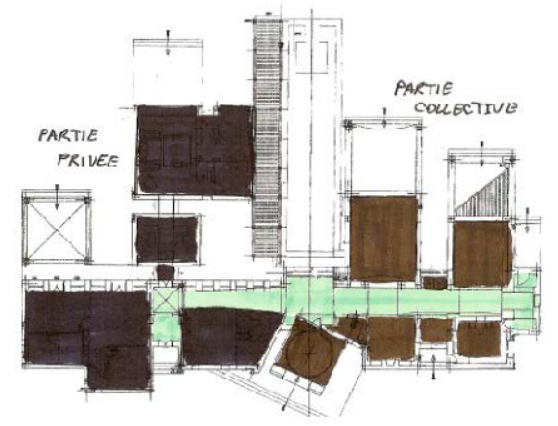

Figure 5: The opposition between private and collective spaces.

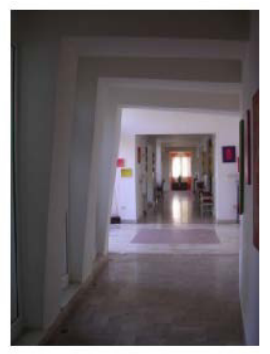

Figure 6: Circulation. 3.1.2.2 Dialectic of the inside and the outside The house is eager to unfold
and fully opens itself onto its garden. It sees itself living. The exterior is brought and fully opens itself onto its garden. It sees itself living. The exterior is brought 
inside and represents itself as a contemplation moment: we look at it from everywhere and at the same time it is a witness to the transition between places, making the spatial experience conscious.

A pathway of light and shades punctuated by greenery The limits of the interior spaces are defined by exterior spaces. Breaches are opened up to define the space and to give light. The designer has conceived simultaneously the architecture of the building and the landscape. He was inspired by images of the traditional house, where the movement from one space to another manifests itself in a constant movement between the inside and the outside through the central patio. Here the movement is not done through the outside, but through a breakaway to the outside.

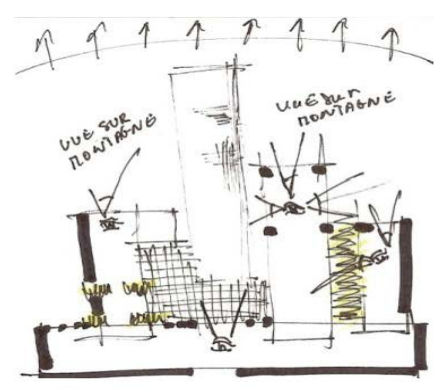

Figure 7: Perspectives of the house onto the landscape.

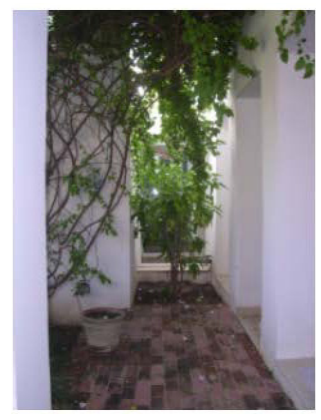

Figure 8: Limits of Figure 9: The entrance. Figure 8: $\begin{array}{ll}\text { Limits of } \\ \text { greenery. }\end{array}$

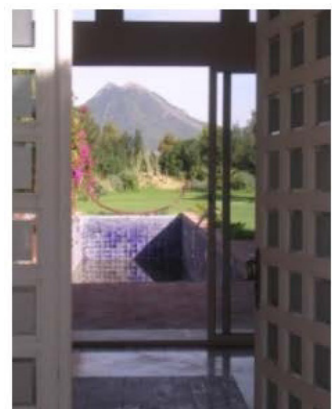

\subsection{Configuration: think building}

\subsubsection{Spatial synthesis of the heterogeneous}

\subsubsection{Poetic reversals: a combination between self-recognition/peripeteia}

Because of his Tunisois origins and his childhood in this suburb of the capital, a former resort of the aristocracy, even the choice to live there today translates somewhere the owner's self-recognition through the site. After years abroad, his choice edifies a homecoming and illustrates the idea of Heidegger, who links the act of living to that of self-identification with an environment: man $d$ wells when he can orientate himself within and identify, or, when he experiences environment as meaningful [6]. Thus, the owner sees himself in the other (the mountain and what it symbolizes) and the act of residing, translating the idea of dwelling, becomes meaningful.

Self-recognition (recognizing themselves in the mountain) is combined with peripeteia (entering through the door) to produce meaning and aesthetic effects. This complicity between man and the place provides the conditions for being on earth [7]. It is particularly appreciable as the entrance setting is a fundamental component of traditional poetics constituting a thickness, which extends in space and organizes it. A new reality inspired by traditional poetics is thus achieved: 
the notion of mask that materialize the architectural form, makes one recognize themselves as modern and at the same time as local. Identification elements relating to individual and collective memory are involved.

3.2.1.2 The innovation/tradition relationship Innovation situates itself between two levels:

The level of architectural composition: in the shaping process of the space, the architect keeps the traditional principle of adding simple geometric forms, yet he integrates nature as a component of the built environment. This does not meet local traditions. The blueprint of the house is shaped by light and green breakaways, and the pathway is punctuated by sequences that emphasize discovery effects. The spatial experience is dramatized and accentuated by the chromatic atmosphere of the lively colors of the owner's own paintings. The house reflects a search for a poetic harmony between man and nature, using greenery as a conceptual element of space as well as concrete.

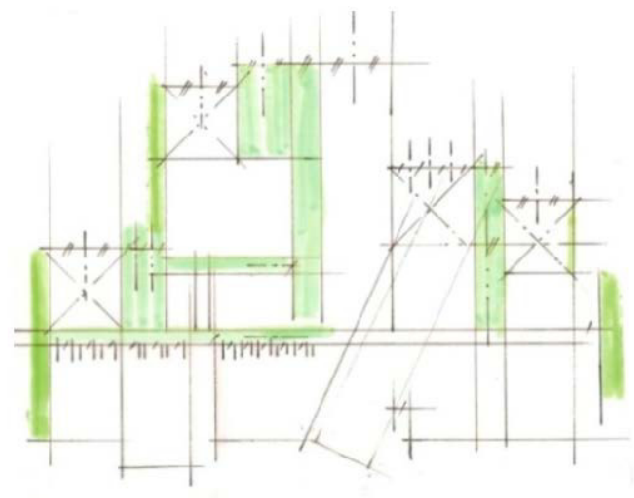

Figure 10: Addition of forms spaced by green strips.

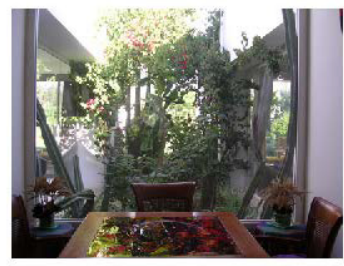

Figure 11: Green sequence.

The level of the relationship between the inside and the outside breaks the traditional box, while respecting the privacy requirements imposed by the $d$ welling which is specific to the site here. Proximity between spaces generated at the same time greenery strips with isolating functionality. Transparency is worked in two ways that could be compared to the pictorial work of cubism which introduces the time dimension in the apprehension of space. Everything is to be seen while it is concealed from the view.

Together, light and greenery help to structure and punctuate space to give it emotional value. Similarly, a reflection on the theme of the mythical patio is achieved, transforming both the form and the function. This transformation keeps the basic poetic structure of centrality and organizing the entire space of the house. The patio is at the same time a reunion moment and the heart of the house. The architecture thereby achieves a dialogue between traditional and modern sources. 


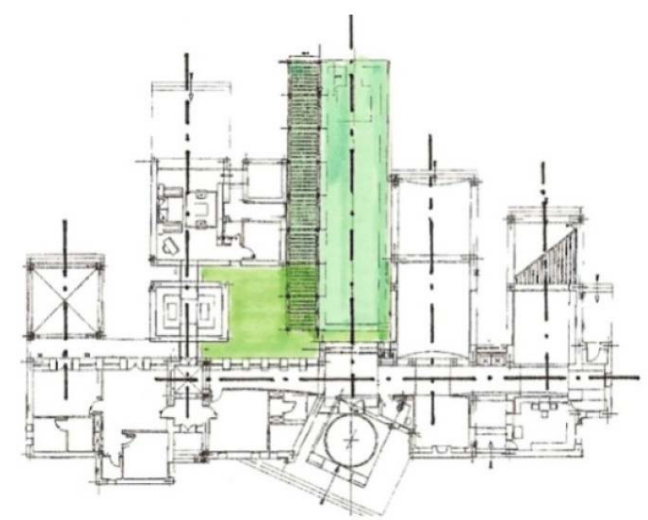

Figure 12: The patio re-interpreted.
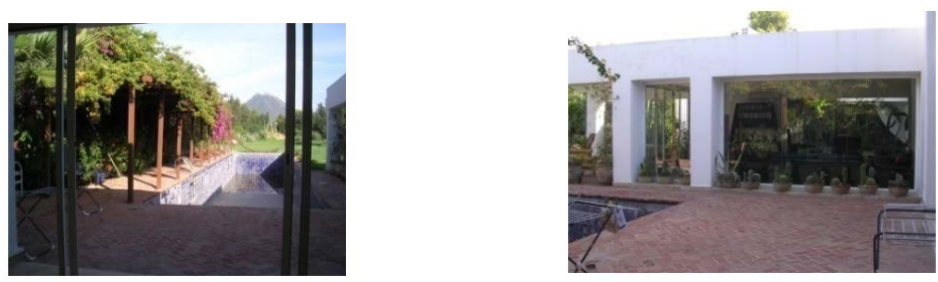

Figure 13: Swimming pool at the Figure 14: Living room opens fully axis of the patio. to the patio.

\subsection{Refiguration: about re-evaluation of $d w e l l i n g$}

The purpose of the interviews conducted with the owner and the architect was to compare what was imagined by the architect and what is lived by the user. Examining these interviews, we were able to infer that the house would not have this atmosphere without the contribution of the owner. It has been conceived while integrating the landscape as part of the built environment design. $\mathrm{He}$ participated in many sketches, making his dream to re-create the home of the past, his dream hut and palace, come true. Therefore, he identifies himself with it completely: he perceives his house as traditional, organized around a patio, and modern, widely opened onto the site.

\section{Conclusion}

In summary, we can say that there is a great deal of thinking on the deep structures of the analyzed house. The architect has managed to transform traditional poetics regardless of style. This has been translated into a reflection on traditional $d$ welling based on interiority and on the relationship between the inside and the outside, which is sacred, ritualized and marked by filtering and protection. The architect worked on the basic themes of patio, centrality, and dialectic relationship between the building and the natural environment. He 
broke the traditional box while respecting the privacy needs imposed by dwelling. The apprehension of landscapes here reports to a sensory and a movement approach. "Self-recognition" and "peripety" were combined to produce a poetics of the "pathway", and not only the form has been transformed but also the function, to adapt them to the requirements of the XXI century. This transformation has used an abstract rhetoric, and the architect tried to achieve this universal creativity phase, characterized by abstraction. His aim started with abstraction and universality to adapt on the one hand some characteristics of the traditional architecture, and on the other hand the owner $d w e l l i n g$ related to use. Moreover, the use of "poetic reversals" has produced a new reality somewhere resting on traditional poetics, re-interpreting in the way interiority. Why is it that our modernity would indeed relegate the interior of the human? Wishing to retreat from the world seems to be a very popular alternative for Tunisians. Has it not been sought by an important figure of modernity, when Le Corbusier continually preached digression from the rule of rationality and radicalism, claiming the primacy of meditation and freedom from the productive logic? It is with this relationship to the world and to ourselves that what we call specific modernity apprehends man's ethical relationship with oneself and his social relationships with others. Therefore, the house does not seek universality, but some a-temporality that would define its own modernity.

Moreover, thinking about specific modernity in architecture necessarily involves talking of spatial identity, identity in itself. Ricœur's work, from Métaphore Vive to Parcours de la Reconnaissance, teaches us that selfunderstanding is an interpretation, and the identity weaved into narrative is that of the dialectic built between 'selfhood' (ipse) and 'sameness' (idem) [8]. If the dynamic between mimesis I, II and III is space-time as we have pointed out, then we are able to ask whether the spatial and temporal components do construct identity. Architecture under this thinking contributes to the construction of identity, through selfhood and sameness, as pointed out philosophically by Rita Messori: being on earth according to dwelling-building in its spatial component is possible through the succession of the three moments of pre, con and refiguration. It is only through this succession that man can find his own identity.

\section{References}

[1] Habermas, J., La modernité un projet inachevé, Critique, Octobre, 950-967, 1981.

[2] Ricœur, P., Architecture et narrativité, Architectonics: Architectura y Hermeneutica, UPC, Barcelone, 9-29, 2003.

[3] Ricœur, P., Temps et récit Tome I, II, III, Paris, Le Seuil, Paris, 1983-1985.

[4] Bachelard, G., La pétique de l'espace, PUF, Paris, 1961.

[5] Venturi R., De l'ambiguité en architecture, Bordas, Paris, 1976.

[6] Norberg-Schulz, Ch., L'art du lieu: architecture et paysage, permanence et mutations, Le Moniteur, Paris, 1997.

[7] Pacquot, T., Demeure terrestre, enquête vagabonde sur l'habiter, Les Edition de l'Imprimeur, Paris, 2005.

[8] Ricœur, P., Parcours de la Reconnaissance, Gallimard, Paris, 2005. 